\title{
$\beta$-adrenergic receptor polymorphisms in susceptibility, response to treatment and prognosis in heart failure: Implication of ethnicity
}

\author{
SABRINA BERNARDEZ PEREIRA, MÔNICA WANDERLEY MONÇORES VELLOSO, SÉRGIO CHERMONT, \\ MÔNICA MARIA PENA QUINTÃO, ROSEMERY NUNES ABDHALA, CAMILA GIRO, \\ THIAGO OLIVEIRA E ALVES, VIVIANE CAMACHO, LUIZA DE FÁTIMA MAIA CONTARATO, \\ FELIPE MONTES PENA, HENRIQUE MILLER BALIEIRO, MARIA LUIZA ROSA GARCIA, \\ ANTÔNIO CLÁUDIO LUCAS DA NÓBREGA, GEORGINA SEVERO RIBEIRO and EVANDRO TINOCO MESQUITA
}

Fluminense Federal University/Antonio Pedro University Hospital, Niterói, Rio de Janeiro CEP 24033-900, Brazil

Received May 17, 2012; Accepted September 21, 2012

DOI: $10.3892 / \mathrm{mmr} .2012 .1120$

\begin{abstract}
Common functional polymorphisms in $\beta$-adrenergic receptor ( $\beta$ AR) genes have been associated with heart failure (HF) phenotypes and pharmacogenetic interactions with $\beta A R$ blockers. This study evaluated the association between $\beta$ AR polymorphisms and carvedilol drug response and prognosis in patients with HF. In this prospective cohort controlled study, 326 volunteers were enrolled [146 HF patients (ejection fraction (EF) $<50 \%$ by Simpson) and 180 healthy controls]. Drug response was evaluated by echocardiography and outcomes were mortality and hospitalization. DNA was extracted from peripheral blood leukocytes, fragments were amplified by the polymerase reaction and genotyped by restriction fragment length polymorphism (RFLP) for Ser49Gly and Arg389Gly $\beta$ AR-1 polymorphisms and Gln27Glu and Arg16Gly $\beta A R-2$ polymorphisms. The study population was in Hardy-Weinberg equilibrium. The survival rate was adjusted using the Kaplan-Meier method. HF patients showed the following characteristics: EF $35 \pm 9 \%$, $69.9 \%$ male, age $59 \pm 13$ years, $50.7 \%$ self-identified as black, $46 \%$ had ischemic etiology. The mean follow-up of 23 months showed 18 mortalities and 46 hospitalizations. The genotypes Glu27Glu (24.7 vs. 6.1\%, $\mathrm{P}=0.0004)$ and Arg16Arg (72.6 vs. $22.8, \mathrm{P}<0.0001)$ of $\beta$ AR2 polymorphisms and Gly49Gly (33.6 vs. $4.3 \%, \mathrm{P}<0.0001$ ) of the $\beta A R 1$ polymorphism were higher in HF patients compared with controls. Patients with hospital admission showed a significantly higher Gly389 allelic frequency ( 54.9 vs. $42.1 \%, \mathrm{P}=0.039)$, and the trend prevailed among patients who succumbed to the disease $(61.1 \%$, $\mathrm{P}=0.047)$. Black patients with the Ser49Ser genotype showed a reduced survival compared with the Gly49Gly or Ser49Gly
\end{abstract}

Correspondence to: Dr Sabrina Bernardez Pereira, Rua Professor Otacílio 94/601, Santa Rosa, Niterói, Rio de Janeiro, CEP 24240-670, Brazil

E-mail: s.bernardez@globo.com

Key words: heart failure, polymorphisms, prognosis, ethnicity genotypes $(\mathrm{P}=0.028)$. There was no association between improved LVEF $>20 \%$ and $\beta A R$ polymorphisms. HF patients with $\beta$-blocker therapy and the Gly389 allele have reduced event-free survival compared to those carrying the Arg389 allele. Additionally, systolic HF outpatients undergoing $\beta$-blocker therapy, self-identified as black and homozygous for Ser49Ser may have reduced event-free survival, while Glu27Glu, Arg16Arg and Gly49Gly genotypes may be associated with risk for HF.

\section{Introduction}

Heart failure (HF) is a clinical syndrome characterized by impaired contractile function of the heart, and represents the final pathway of a variety of diseases.

The sympathetic nervous system and its neurotransmitters, noradrenaline and adrenaline, play a key role in the development and prognosis of heart failure. Chronic neurohumoral activation with high catecholamine levels increases afterload, as well as myocardial consumption of energy, hypertrophy and apoptosis of myocytes, which leads to deterioration of cardiac function, thus triggering a vicious cycle (1). Sympathetic activation is observed from the early stages of HF, with rates of catecholamine associated with functional class and prognosis of this disease (2).

The persistent sympathetic activation in HF will also cause increased heart rate, arteriolar vasoconstriction with increased peripheral vascular resistance and renal function, reduced blood flow and sodium excretion with a consequent increase in blood volume, venous return and ventricular pressures and volumes (3).

The beneficial effects of $\beta$-blocking agents appear to be due to their ability to prevent the deleterious effects of catecholamine on the heart and circulation. However, several studies have shown that the response to $\beta$-blockers is variable among patients and this is partly explained by genetic changes, mainly related to the polymorphisms of the $\beta$-adrenergic receptor gene (ADRB).

The most commonly studied polymorphism in HF is the ADRB1 polymorphism Arg389Gly, which is related to a poorer response to bucindolol in patients with the Gly389 
variant (4). Recently, several other functionally relevant polymorphisms of adrenergic receptors $\alpha 2, \beta 1$ and $\beta 2$ and their specific genotypes were found to be associated with incidence and clinical severity of HF (5).

Additionally, there has been debate concerning the impact of ethnicity on the efficacy of $\beta$-blockers. Certain studies suggest that many of the perceived differences in the efficacy of $\beta$-blockers, as well as the variability of responses to $\beta$-blockers among African-Americans, may be attributed to genetic variations that affect $\beta$-receptors and their signaling pathways.

The aim of this study was to evaluate the polymorphisms of $\beta$-adrenergic receptors in the risk of development of HF and response to therapy and prognosis in patients with left ventricular systolic dysfunction using carvedilol.

\section{Materials and methods}

\section{Study population}

Patients. A total of 146 patients with heart failure caused by systolic dysfunction from the Heart Failure Clinic at the Fluminense Federal University were enrolled in this study between December 2005 and March 2009.

In this prospective cohort, the inclusion criteria were: age $\geq 18$ years; patients with a history and physical examination compatible with HF; left ventricular ejection fraction (LVEF) $\leq 50 \%$ by Simpson's method echocardiography. The exclusion criteria were situations that could affect prognosis or drug response, regardless of $\beta$-blocker use: implantation of a cardiac resynchronization therapy device (CRTD) within 3 months prior to admission in this study or intent to implant a CRTD; active myocarditis; episode of aborted sudden death or presence of defibrillators; indication of percutaneous or surgical coronary intervention within the 3 months prior or 6 months following admission; intolerance to carvedilol therapy on admission.

Peripheral blood was obtained for DNA isolation and genotyping. The demographic data recorded were gender, age and self-identified ethnicity. Clinical data assessed were smoking, body mass index, presence of hypertension, coronary artery disease, diabetes mellitus, chronic renal failure, anemia, atrial fibrillation and use of cardiovascular medications. Patients with a history of acute myocardial infarction, percutaneous or surgical coronary intervention were considered as having coronary artery disease. All patients underwent standard treatment for congestive heart failure. Carvedilol was the $\beta$-blocker used and a target dose of $25 \mathrm{mg}$ twice daily was considered or the maximum tolerable dose.

Control group. The control group consisted of 180 healthy individuals, without structural heart disease according to clinical evaluation guided by history, physical examination and electrocardiogram. The exclusion criteria in this group were age $<18$ years and presence of cardiovascular risk factors (dyslipidemia, hypertension, diabetes mellitus, atherosclerotic disease, family history of cardiomyopathy).

Ethics considerations. This investigation conformed to the principles outlined in the Declaration of Helsinki, the Institutional Ethics Committee of Faculty of Medicine/ Antonio Pedro University Hospital approved the protocol and all patients signed an informed consent form prior to entering the study.

Echocardiographic assessment. Echocardiographic examinations were performed by two experienced echocardiographers, both on admission and following six months of monitoring, in accordance with the guidelines of the European Society of Cardiology (6). The analyses made in this study were: left ventricular cavity diameters in systole and diastole and left atrium and LVEF by volume calculation (Simpson) (Vivid 3, GE Medical Systems Ultrasound, WI, USA).

Follow-up. Patients were followed up for a minimum period of 12 months and a maximum of 40 months to evaluate the outcomes of hospitalization as well as death. The information was registered through the subsequent visits (in case of hospitalization) or phone or medical records (in the case of death).

The patients who met the inclusion criteria and consented to participate in the study were submitted to laboratory exams and genetic evaluation, and drug therapy was optimized or initiated.

Six months after the study onset, patients were reassessed with clinical, laboratory and echocardiographic exams. We considered echocardiographic improvement compared to the admission exam as an increase in LVEF $\geq 20 \%$ and reduction of left cavity diameters $\leq 5 \%$.

Genotyping of the $\beta$-adrenergic polymorphism. The samples were subjected to cell lysis with $1000 \mu$ l of Tris-1 (Tris-HCl $10 \mathrm{mM} \mathrm{pH} 8.0, \mathrm{KCl} 10 \mathrm{mM}, \mathrm{MgCl}_{2} 10 \mathrm{mM}$, EDTA $2 \mathrm{mM}$ $\mathrm{pH}$ 8.0) containing Triton X-100 2.5\%. Following centrifugation at 5,000 rpm for $5 \mathrm{~min}$ in a Beckman centrifuge, the cell nuclei were lysed with $200 \mu \mathrm{l}$ of Tris-2 containing SDS $1 \%$. The proteins were removed by saline precipitation with $100 \mu \mathrm{l}$ $\mathrm{NaCl} 5 \mathrm{M}$. The DNA present in the supernatant was isolated by ethanol precipitation and finally resuspended in $100 \mu \mathrm{l} \mathrm{TE}$ (Tris-HCl $10 \mathrm{mM}$ and $1 \mathrm{mM}$ EDTA, $\mathrm{pH}$ 8.0) and stored at $-20^{\circ} \mathrm{C}$ until use.

Following extraction, the integrity of DNA samples was analyzed by an electrophoresis system (Bio-Rad electrophoresis) in $0.8 \%$ agarose gel in TBE $1 \mathrm{X}$ (Tris- $\mathrm{HCl} 90 \mathrm{mM}$, $90 \mathrm{mM}$ boric acid and $2 \mathrm{mM}$ EDTA) stained with ethidium bromide.

The ADRB1 polymorphisms [Arg389Gly (rs1801253); Ser49Gly (rs1801252)] and ADRB2 polymorphisms [Gln27Glu (rs1042713); Arg16Gly (rs1042713)] were analyzed by polymerase chain reaction and restriction fragment length polymorphism (PCR-RFLP) $(7,8)$. The PCR was performed in a total volume of $25 \mu \mathrm{l}$, utilizing 50-100 ng genomic DNA, after adjusting the concentration, 1 unit of Fermentas Taq DNA polymerase, reaction buffer $\left(50 \mathrm{mM} \mathrm{KCl}, 1.5 \mathrm{mM} \mathrm{MgCl}_{2}\right.$ and $10 \mathrm{mM}$ Tris- $\mathrm{HCl}$ ), $200 \mu \mathrm{M}$ of each deoxynucleotide (dATP, dCTP, dGTP and dTTP) and 15 pmol of each oligonucleotide.

The conditions of amplification and digestion for the identification of the polymorphisms are detailed in Table I. The wild allele was defined according to the allele frequency of the study population.

Statistical analysis. The correlation between clinical variables and genotype with the outcomes and therapeutic responses 
Table I. Conditions of amplification and digestion for the identification of the $\beta$-adrenergic receptor polymorphisms.

\begin{tabular}{|c|c|c|c|c|}
\hline & \multicolumn{2}{|c|}{ ADBR1 } & \multicolumn{2}{|c|}{ ADBR2 } \\
\hline & Arg389Gly & Ser49Gly & Glu27Gln & Arg16Gly \\
\hline Technique & PCR-RFLP & PCR-RFLP & PCR-RFLP & PCR-RFLP \\
\hline Amplified product (bp) & 530 & 564 & 353 & 201 \\
\hline \multicolumn{5}{|l|}{ Cycling } \\
\hline Initial denaturation & $94^{\circ} \mathrm{C}-5 \mathrm{~min}$ & $94^{\circ} \mathrm{C}-5 \mathrm{~min}$ & $94^{\circ} \mathrm{C}-5 \mathrm{~min}$ & $94^{\circ} \mathrm{C}-5 \mathrm{~min}$ \\
\hline Denaturation $^{\mathrm{a}}$ & $94^{\circ} \mathrm{C}-30 \mathrm{sec}$ & $94^{\circ} \mathrm{C}-30 \mathrm{sec}$ & $94^{\circ} \mathrm{C}-1 \mathrm{~min}$ & $94^{\circ} \mathrm{C}-1 \mathrm{~min}$ \\
\hline Annealing ${ }^{\mathrm{a}}$ & $58^{\circ} \mathrm{C}-30 \mathrm{sec}$ & $61^{\circ} \mathrm{C}-30 \mathrm{sec}$ & $56^{\circ} \mathrm{C}-60 \mathrm{sec}$ & $56^{\circ} \mathrm{C}-60 \mathrm{sec}$ \\
\hline Extension $^{\mathrm{a}}$ & $72^{\circ} \mathrm{C}-1 \mathrm{~min}$ & $72^{\circ} \mathrm{C}-1 \mathrm{~min}$ & $72^{\circ} \mathrm{C}-1 \mathrm{~min}$ & $72^{\circ} \mathrm{C}-1 \mathrm{~min}$ \\
\hline Final extension & $72^{\circ} \mathrm{C}-7 \mathrm{~min}$ & $72^{\circ} \mathrm{C}-7 \mathrm{~min}$ & $72^{\circ} \mathrm{C}-7 \mathrm{~min}$ & $72^{\circ} \mathrm{C}-7 \mathrm{~min}$ \\
\hline Restriction enzyme & BCG1 & Eco0109I & Fnu4HI & BsrDI \\
\hline $\begin{array}{l}\text { SNP effect in the } \\
\text { DNA sequence }\end{array}$ & $\begin{array}{c}\text { Abolishes } \\
\text { binding site }\end{array}$ & $\begin{array}{c}\text { Abolishes } \\
\text { binding site }\end{array}$ & $\begin{array}{c}\text { Abolishes } \\
\text { binding site }\end{array}$ & $\begin{array}{c}\text { Creates } \\
\text { binding site }\end{array}$ \\
\hline Fragments of the wild allele (bp) & $342,154,34$ & 345,219 & $27,55,97,174$ & $14,56,131$ \\
\hline Fragments of the mutante allele (bp) & 530 & 564 & $27,97,229$ & $14,23,56,108$ \\
\hline Digestion temperature $\left({ }^{\circ} \mathrm{C}\right)$ & 37 & 37 & 37 & 37 \\
\hline Digestion time (h) & 20 & 20 & $2 \mathrm{~h}$ & 20 \\
\hline
\end{tabular}

${ }^{\mathrm{a}} 0$ cycles. PCR, polymerase chain reaction; RFLP, restriction fragment length polymorphism; bp, base pairs; SNP, single-nucleotide polymorphism.

Table II. Clinical, laboratory and echocardiographic variables of the patient group.

\begin{tabular}{lc}
\hline Variable & Mean \pm SD \\
\hline Age (years) & $58.5 \pm 13.0$ \\
BMI $\left(\mathrm{kg} / \mathrm{m}^{2}\right)$ & $25.9 \pm 5.2$ \\
SBP $(\mathrm{mmHg})$ & $129.7 \pm 26.1$ \\
DBP $(\mathrm{mmHg})$ & $80.2 \pm 15.3$ \\
HR $(\mathrm{bpm})$ & $75.4 \pm 11.6$ \\
Uric acid $(\mathrm{mg} / \mathrm{dl})$ & \\
Female & $6.3 \pm 2.3$ \\
Male & $7.0 \pm 2.1$ \\
Creatinine (mg/dl) & $1.3 \pm 1.0$ \\
Sodium (mEq/l) & $139.2 \pm 3.7$ \\
Hemoglobin (g/dl) & \\
Female & $12.7 \pm 1.5$ \\
Male & $13.9 \pm 1.8$ \\
Admission echocardiography & \\
Left atria (mm) & $4.6 \pm 0.8$ \\
LVEDD (mm) & $6.8 \pm 1.0$ \\
LVESD (mm) & $5.5 \pm 1.1$ \\
LVEF (\%) & $35.3 \pm 9.3$ \\
\end{tabular}

BMI, body mass index; SBP, systolic blood pressure; DBP, diastolic blood pressure; HR, heart rate; bpm, beat per minute; LVEDD, left ventricular end diastolic diameter; LVESD, left ventricular end systolic diameter; LVEF, left ventricular ejection fraction. (univariate and multivariate) was assessed by the following methods: i) for comparison with categorical data the $\chi^{2}$ test or Fisher's exact test were applied; ii) for comparison with numerical data we used the Student's t-test for independent samples, and iii) logistic regression analysis was used to identify independent variables that predict (or explain) the outcomes for therapeutic response.

Kaplan-Meier survival curve and log-rank tests were used for survival analysis and to estimate the difference between the survival probabilities of ADRB1 polymorphisms and self-identified ethnicity.

The $\chi^{2}$ test showed that the genotype frequencies of polymorphisms of genes ADRB1 and ADRB2 were in agreement with the assumptions of Hardy-Weinberg.

The criterion for determining significance was the level of 5\%. Statistical analysis was conducted using the statistical software SAS ${ }^{\circledR}$ System.

\section{Results}

Baseline demographics. Of the 146 patients included in the study, 140 remained until the completion, with 6 losses occurring due to loss of contact or waiver monitoring. The mean age of the cohort was $59 \pm 13$ years; $72.9 \%$ were male, $46 \%$ were ischemic (no patient had Chagas disease) and $49.3 \%$ were non-black (self-identified). In total, 94\% of patients were treated with either an ACE inhibitor or an angiotensin receptor blocker, and all the patients were taking $\beta$-blockers. All patients had the maximum tolerated dose. Clinical, laboratory and echocardiographic variables are shown in Table II. 
Table III. ADBR1 and ADBR2 genotypes in control and patient groups.

\begin{tabular}{|c|c|c|c|c|c|}
\hline & & & Controls & Patients & \\
\hline Gen & Polymorphisms & Genotype & $\mathrm{n}(\%)$ & $\mathrm{n}(\%)$ & P-value \\
\hline \multirow[t]{6}{*}{ ADBR 1} & Arg389Gly & ArgArg & $82(45.6)$ & $71(48.6)$ & 0.84 \\
\hline & & ArgGly & $77(42.80$ & $58(39.8)$ & \\
\hline & & GlyGly & $21(11.7)$ & 17 (11.6) & \\
\hline & Ser49Gly & SerSer & $129(93.5)$ & $33(22.60$ & $<0.0001$ \\
\hline & & SerGly & $43(31.2)$ & $64(43.8)$ & \\
\hline & & GlyGly & $6(4.3)$ & $49(33.6$ & \\
\hline \multirow[t]{6}{*}{ ADBR2 } & Gln27Glu & GlnGln & $95(52.8)$ & 48 (32.9) & 0.0004 \\
\hline & & GlnGlu & $74(41.1)$ & $62(42.4)$ & \\
\hline & & GluGlu & $11(6.1)$ & $36(24.7$ & \\
\hline & Arg16Gly & ArgArg & $41(22.8)$ & $106(72.6)$ & $<0.0001$ \\
\hline & & ArgGly & $76(42.2)$ & $37(25.3)$ & \\
\hline & & GlyGly & $63(35.0)$ & $3(2.1)$ & \\
\hline
\end{tabular}
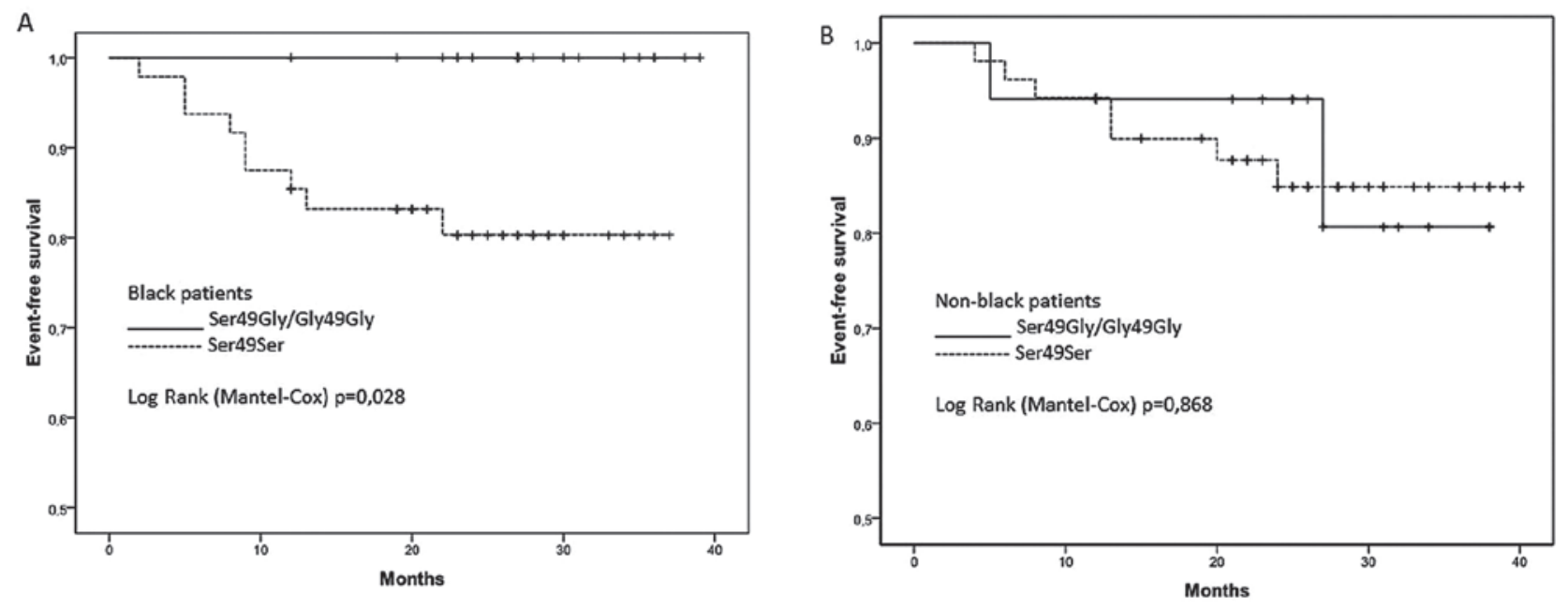

Figure 1. Event-free survival according to the ADBR1 polymorphism Ser49Gly and self-identified ethnicity. (A) Black patients; (B) non-black patients.

Clinical characteristics. With regard to comorbidities associated with HF, there was a predominance of hypertension (73.6\%), followed by coronary artery disease $(42.1 \%)$, diabetes mellitus type II (34.3\%), anemia (25.7 \%), chronic renal failure (16.4\%) and atrial fibrillation (15.7\%).

In assessing the functional class, it was observed that the majority of patients included were in functional class I or II (75\%) according to the New York Heart Association (NYHA) classification. On the laboratory tests, only the mean serum uric acid for both genders was higher than the normal range. Echocardiogram performed at inclusion of the study demonstrated the prevalence of patients with severe LV systolic dysfunction (mean LVEF, 35.3\%). Only advanced functional class $[R R=3.90(1.73-8.80), P=0.001]$ was significant for predicting hospitalization. The other variables showed no independent contribution.

Analysis of genotype prevalence in control and patient groups. In order to establish the prevalence of genotypes for the ADRB1 and ADRB2 polymorphisms between cases and controls, 180 healthy subjects were analyzed. The control group showed that the Gln27Gln genotype $(52.8 \%)$ was significantly higher compared with the case group (32.9\%) $(\mathrm{P}=0.0004)$. Moreover, the number of cases presenting the Glu27Glu genotype $(24.7 \%)$ was significantly higher than the control group (6.1\%). In the same way, the patient group had a higher prevalence of Gly16Gly and Gly49Gly genotypes $(\mathrm{P}<0.0001)$ when compared with the control group. No association was found for Arg389Gly genotypes (Table III).

\section{Outcomes}

Event-free survival. During follow-up, 15 patients succumbed to the disease $(10.7 \%)$ and 46 patients required hospitalization $(32.9 \%)$.

Analysis of outcomes in relation to allele frequency. There was no statistical significance in the analysis of the correlation between $>20 \%$ LVEF improvement and allele frequencies of the different $\beta$-adrenergic receptors polymorphisms. 
In the analysis of clinical outcomes and polymorphisms for ADRB1 Arg389Gly, no significant association was observed with the $\chi^{2}$ test between mortality after 12 months and allele frequency of $\mathrm{Arg} / \mathrm{Gly}$, at $5 \%(\mathrm{P}=0.065)$. However, according to Fisher's exact test, it was found that patients who succumbed to the disease had a significantly higher Gly389 allele frequency (61.1\%) than the group that did not (44.7\%), $\mathrm{P}=0.047$.

Additionally, and reinforcing the first finding, it was observed that patients admitted to hospital after 12 months showed a Gly389 allele frequency that was significantly higher $(54.9 \%)$ than the group without hospitalization (42.1\%), $\mathrm{P}=0.039$. In the evaluation of ADRB2 and ADRB1 Ser49Gly polymorphisms, the difference was not statistically significant for the analysis of clinical outcomes and allele frequency.

Evaluation of survival or event-free survival in relation to genotypes. It was observed that there were no significant differences in survival between the two subgroups of ADRB1 Ser49Gly (Ser49Ser vs. Ser49Gly + Gly49Gly). The subgroup with the Ser49Ser genotype presented a reduced survival rate compared with the subgroup with a non-Ser49Ser genotype; however, this showed no statistical significance $(\mathrm{P}=0.085)$.

The subgroup with the presence of the Gly389 allele had lower survival than the subgroup without the Gly389 allele (Arg389Arg), but there was no significant difference in survival between the two subgroups of genotype ADRB1 Arg389Gly (Gly389Gly + Arg389Gly vs. Arg389Arg) (P=0.054).

There was no significant difference in the evaluation of the polymorphisms studied for the ADRB2 gene and event-free survival.

Assessment of survival in relation to polymorphisms of the $\beta$-adrenergic receptors and self-identified ethnicity. In the analysis of hospital outcomes in relation to polymorphisms of the $\beta$-adrenergic receptors, we found no significant difference between the studied groups; however, the survival analysis, shown in Fig. 1, revealed that homozygous ADRB1 Ser49Ser patients who described themselves as black had lower survival compared to homozygous Gly49Gly and heterozygous Ser49Gly patients $(\mathrm{P}=0.028)$. There was no such difference between the patients who described themselves as non-black $(\mathrm{P}=0.868)$.

In the analysis for polymorphism Arg389Gly, we found a higher mortality rate among patients who described themselves as black and who had the presence of 1 or 2 Gly389 alleles $(\mathrm{P}=0.06)$, although this was not statistically significant, while the same was not observed in the patients who described themselves as non-black $(\mathrm{P}=0.33)$.

\section{Discussion}

For a considerable number of cardiovascular diseases, it has been proposed that both susceptibility to disease and individual variability in relation to the treatment were associated in part to genetic polymorphisms, particularly those polymorphisms that are related to neurotransmitter receptors.

The central role of the sympathetic nervous system and its receptors in HF makes the genetic polymorphisms of these receptors strong candidates for risk factors and predictors of response to treatment of this disease.

The allelic prevalence studies in different populations have shown that for ADRB1 Arg389Gly polymorphism, the allele frequency of $\operatorname{Arg} 389$ is greater than of Gly389, at 70 and $30 \%$ respectively, and there was a higher frequency for the Gly389 allele in African-Americans (42\%) compared to Caucasians (27\%). In the control group of this study, we found a similar allele frequency distribution to Hispanic-Americans $(67 \%$ for Arg389 and 33\% for Gly389) (9). With regard to the allelic distribution of the gene polymorphism ADRB1 Ser49Gly, Moore et al (10) demonstrated no difference in the prevalence of the Gly49 allele among Caucasians and Asians (15\%). In a multiethnic population, such as in Brazil, the Gly49 allelic frequency is equal, whereas, among African-Americans the frequency for the same allele is $13 \%$.

The estimated frequency of the Arg16 variant is 39.3\% in Caucasians, $49.2 \%$ in African Americans and 51.0\% among Chinese patients. The estimated frequency of the Glu allele is $24.6 \%$ among Caucasian, $18.7 \%$ among black and 9\% among Chinese patients. In this study the estimated frequency of the Arg16 variant is $44 \%$ and $27 \%$ for the Glu allele in a Brazilian population (11)

In the investigation of gene polymorphisms of ADRB1 and risk for development of $\mathrm{HF}$, no association between polymorphism Arg389Gly and susceptibility to HF was found. The same finding had been shown by Small et al (12) in an evaluation of 159 patients with HF (ischemic and idiopathic) and 189 controls; and Tesson et al (13) in 426 patients with idiopathic dilated cardiomyopathy. For the Ser49Gly polymorphism, Borjesson et al (14) concluded that the prevalence of Ser49Gly was similar in 184 patients with idiopathic HF and 77 controls. However, Podlowski et al (15) observed that the presence of the Gly49 allele was more prevalent in patients with idiopathic cardiomyopathy, as was found in this study.

Regarding susceptibility to $\mathrm{HF}$ and gene polymorphisms of ADRB2, Liggett et al (16) studied the effect of these in 259 patients with idiopathic or ischemic HF and concluded that Arg16Gly and Gln27Glu polymorphisms were not associated with risk of developing HF or with prognosis, fitting with the conclusion of other studies that have made this analysis. Forleo et al (17), after analyzing haplotypes of Gly16Glu27, concluded that patients with dilated cardiomyopathy had a higher risk of developing HF.

In this population, a higher prevalence of the genotypes Glu27Glu and Gly16Gly was found among patients with HF compared to healthy volunteers. The same fact was found by Mogara et al (18) in a study conducted in the Latin American population, where the presence of Glu allele was considered a possible predictor of risk for HF.

Studies in other populations indicate a higher susceptibility to develop hypertension in carriers of the Glu27 and Gly16 alleles. Bray et al (19) showed higher frequencies for the Gly16 and Glu27 alleles in hypertensive compared with normotensive patients, and the odds ratio for the occurrence of hypertension was $1.80(\mathrm{P}=0.023)$ for the Glu27 allele. Therefore, as the prevalence of hypertension was $74 \%$ among individuals with HF in our study, this comorbidity could be attributed to the higher prevalence of Glu27Glu and Gly16Gly genotypes and not directly related to HF.

Studies are inconclusive on reverse remodeling in patients with $\mathrm{HF}$ and polymorphisms of the $\beta$-adrenergic receptors. While some have shown that improvement in LVEF and reduction of cavity diameters with the use of $\beta$-blockers is associated 
with the presence of the allele Arg389, some trials such as MERITH found no association of these polymorphisms with reverse remodeling. Other studies showed improvement in LVEF in the presence of the Gly49 and Glu27 alleles, but this was not confirmed by larger studies $(20,21)$.

In this population no association was found for any of the polymorphisms studied with improvement in LVEF following six months of treatment with carvedilol, both for assessing genotypes and allele frequency.

For the assessment of prognosis and ADRB1 polymorphisms, one sub-study of BEST analyzed 1,040 patients for the polymorphism Arg389Gly and showed that those patients homozygous for Arg389 and treated with bucindolol had a significant reduction in mortality compared with placebo, while there was no difference in same evaluation for the homozygous Gly389 (4). As a result of this study, the FDA approved the use of this genetic test for patients with HF.

In a retrospective analysis of 375 patients with dilated cardiomyopathy receiving $\beta$-blockers and 492 controls, a significant association was observed between survival and the polymorphism Ser49Gly, and the Ser49 variant was associated with reduced 5-year survival. However, this study was aimed at patients with HF with preserved LVEF and did not specify the use of $\beta$-blockers in the study (22). In the present study, the assessment of prognosis in relation to outcomes of death and hospitalization over an average of 23 months had a decreased survival in patients with the Gly389 allele and tendency to mortality for those with the genotype.

Ethnic differences and indicators of socioeconomic status cannot fully explain the excess mortality in the self-identified black population compared to the white population, particularly mortalities from cardiovascular disease and complications such as heart failure. This finding has reinforced the theory that the racial differences in cardiovascular events are mediated by genetic factors that determine disease severity and response to medications (23).

In the analysis of survival, Ser49Gly polymorphism and self-identified ethnicity, it was observed that black patients with the Ser49Ser homozygote had a poorer survival compared to non-black patients with the same genotype. This corroborates the interaction of gene-ethnicity-response to drugs that had already been described in relation to the polymorphism of nitric oxide synthase and favorable response to the hydralazine-nitrate combination in African-American HF patients. The results of Genetic Risk Assessment of Heart Failure (GRAHF) study suggested that genetic variation for the enzyme nitric oxide synthase 3 affects the progression to $\mathrm{HF}$ and may impact the therapeutic efficacy of the nitratehydralazine combination (24).

The studies are controversial regarding the response to $\beta$-blockers according to ethnicity. The BEST study showed an $18 \%$ increase in survival of non-African-Americans $(\mathrm{P}=0.01)$ vs. a $17 \%$ reduction in survival of African-Americans $(\mathrm{P}=0.27)$ with the use of bucindolol compared with placebo (25). The U.S. Carvedilol and COPERNICUS studies showed no difference in drug response in favor of $\beta$-blockers in relation to whether or not patients were African-American $(26,27)$.

It is worth noting that the studies conducted to evaluate the effectiveness of $\beta$-blockers in HF include a significantly smaller number of African-Americans, which may compromise the analysis of drug response according to ethnicity (28). Moreover, none of the studies has been developed specifically to test whether there was any difference in therapeutic response between ethnic groups. The comparisons made by analysis of subgroups are not involved in the original design of the study.

Another fact that should be taken into account is the different pharmacological actions of $\beta$-blockers. Carvedilol is a nonselective $\beta$-adrenergic blocking agent with $\alpha 1$-blocking activity and is a multiple-action neurohormonal antagonist. It has sympathomimetic activity besides membrane stabilizing properties, and is a potent antioxidant and neutralizer of oxygen radicals, which may explain the better results in African-Americans; whereas, bucindolol is a phenoxypropanolamine with potent non-selective $\beta$-antagonist activity but mild vasodilatory properties (29).

Finally, ethnic differences in drug response may be due to genetic differences and the environmental effects on individuals, as well as the pathogenesis of the disease itself. The genetic differences between ethnic groups, in turn, result from differences in the distribution of polymorphisms that are related to both the enzymes responsible for drug metabolism as well as the recipients of these medications. For example, African-Americans and Africans have a high frequency of the CYP2D6 allele, which encodes an enzyme deficiency. This allele is virtually absent in Caucasians and Asians. This is particularly notable as regards the response to carvedilol in black patients, and since CYP2D6 is responsible for the metabolism of one isomer of this product, it may contribute to the efficacy and toxicity, according to the genotype (30).

Prospective validation of predictive impact of genetic variations is necessary prior to implementation of routine treatments that are genetically individualized.

HF patients with $\beta$-blocker therapy and the Gly389 allele have worse outcome, with reduced event-free survival compared to those carrying the Arg389 allele. HF patients treated with carvedilol, self-identified as black and homozygous for Ser49Ser may have reduced survival compared to non-black patients with the same genotype. Additionally, the genotypes ADRB2 Arg16Arg and Glu27Glu and ADRB1 Gly49Gly had the highest prevalence in the group of HF patients compared to the control group. However, further information is required to confirm these results.

\section{Acknowledgements}

This study was supported by the Rio de Janeiro Research Assistance Foundation (FAPERJ) and the Science and Technology Department of the Brazilian Health Ministry in the Molecular Genetics Program applied to the Brazilian Health System. Carvedilol was donated by the pharmaceutical Co., Baldacci Inc., which, however, did not participate directly or indirectly in the design, analysis or publication of the results in this study.

\section{References}

1. El Armouche A and Eschenhagen T: $\beta$-Adrenergic stimulation and myocardial function in the failing heart. Heart Fail Rev 14: 225-241, 2009. 
2. Cohn, JN, Levine TB and Olivari MT: Plasma norepinephrine as a guide to prognosis in patients with chronic congestive heart failure. N Engl J Med 311: 819-823, 1984.

3. Triposkiadis F, Karayannis G, Giamouzis G, Skoularigis J, Louridas $\mathrm{G}$ and Butler J: The sympathetic nervous system in heart failure physiology, pathophysiology, and clinical implications. J Am Coll Cardiol 54: 1747-1762, 2009.

4. Liggett SB, Mialet-Perez J, Thaneemit-Chen S, et al: A polymorphism within a conserved beta(1)-adrenergic receptor motif alters cardiac function and betablocker response in human heart failure. Proc Natl Acad Sci USA 103: 11288-11293, 2006.

5. McNamara DM: Emerging role of pharmacogenomics in heart failure. Curr Opin Cardiol 23: 261-268, 2008

6. Lang RM, Bierig M, Devereux RB, et al: Recommendations of chamber quantification. Eur J Echocardiogr 7: 79-108, 2006.

7. De Groote P, Lamblin N, Helbecque N, et al: The impact of betaadrenoreceptor gene polymorphisms on survival in patients with congestive heart failure. Eur J Heart Fail 7: 966-973, 2005.

8. Maqbool A, Hall A, Ball S and Balmforth AJ: Common polymorphisms of betal-adrenoceptor: identification and rapid screening assay. Lancet 353: 897, 1999.

9. Xie HG, Dishy V, Sofowora G, et al: Arg389Gly beta 1-adrenoceptor polymorphism varies in frequency among different ethnic groups but does not alter response in vivo. Pharmacogenetics 11 191-197, 2001.

10. Moore JD, Mason DA, Green SA, Hsu J and Liggett SB: Racial differences in the frequencies of cardiac beta(1)-adrenergic receptor polymorphisms: analysis of $\mathrm{c} 145 \mathrm{~A}>\mathrm{G}$ and $\mathrm{c} 1165 \mathrm{G}>\mathrm{C}$. Hum Mutat 14: 271, 1999.

11. Small KM, McGraw DW and Liggett SB: Pharmacology and physiology of human adrenergic receptor polymorphisms. Annu Rev Pharmacol Toxicol 43: 381-411, 2003.

12. Small KM, Wagoner LE, Levin AM, Kardia SL and Liggett SB: Synergistic polymorphisms of $\beta 1$ - and $\alpha 2 \mathrm{C}$-adrenergic receptors and the risk of congestive heart failure. N Engl J Med 347: $1135-1142,2002$.

13. Tesson F, Charron P, Peuchmaurd M, et al: Characterization of a unique genetic variant in the betal-adrenoceptor gene and evaluation of its role in idiopathic dilated cardiomyopathy. Cardigene Group. J Mol Cell Cardiol 31: 1025-1032, 1999.

14. Börjesson M, Magnusson Y, Hjalmarson A and Andersson B: A novel polymorphism in the gene coding for the beta(1)-adrenergic receptor associated with survival in patients with heart failure. Eur Heart J 21: 1853-1858, 2000.

15. Podlowski S, Wenzel K, Luther HP, et al: Beta1-adrenoceptor gen variations: a role in idiopathic dilated cardiomyopathy? J Mol Med 78: 87-93, 2000.

16. Liggett SB, Wagoner LE, Craft LL, Hornung RW, Hoit BD, McIntosh TC and Walsh RA: The Ile164 beta2-adrenergic receptor polymorphism adversely affects the outcome of congestive heart failure. J Clin Invest 102: 1534-1539, 1998.
17. Forleo C, Resta N, Sorrentino S, et al: Association of $\beta$-adrenergic receptor polymorphisms and progression of heart failure in patients with idiopathic dilated cardiomyopathy. Am J Med 117: 451-458, 2004

18. Moraga F, Troncoso R, Mellado R, et al: Interactions between beta1 and beta2 adrenergic receptor polymorphisms as risk factors for chronic heart failure. Rev Med Chil 136: 1371-1380, 2008 (In Spanish)

19. Bray MS, Krushkal J, Li L, et al: Positional genomic analysis identifies the beta(2)-adrenergic receptor gen as a susceptibility locus for human hypertension. Circulation 101: 2877-2882, 2000.

20. Terra SG, Hamilton KK, Pauly DF, et al: $\beta 1$-Adenergic receptor polymorphisms and left ventricular remodeling changes in response to $\beta$-blocker therapy. Pharmacogenet Genomics 15: 227-234, 2005

21. White HL, de Boer RA, Maqbool A, et al: An evaluation of the beta-1 adrenergic receptor Arg389Gly polymorphism in individuals with heart failure: a MERIT-HF sub-study. Eur J Heart Fail 5: 463-468, 2003

22. Magnusson Y, Levin MC, Eggertsen R, Nyström E, Mobini R, Schaufelberger M and Andersson B: Ser49Gly of $\beta 1$-adrenergic receptor is associated with effective $\beta$-blocker dose in dilated cardiomyopathy. Clin Pharmacol Ther 78: 221-231, 2005.

23. Latado AL, Lopes MB, Passos LC and Lopes AA: Does any evidence exist to treat heart failure based on race or ethnicity? Rev Assoc Med Bras 55: 110-116, 2009 (In Portuguese).

24. McNamara DM, Tam W, Sabolisnski ML, et al: Endothelial nitric oxide synthase (NOS3) polymorphisms in African Americans with heart failure: results from the A-HeFT trial. J Card Fail 15: 191-198, 2009.

25. Beta-Blocker Evaluation of Survival Trial Investigators: A trial of the beta-blocker bucindolol in patients with advanced chronic heart failure. N Engl J Med 344: 1659-1667, 2001.

26. Cohn JN, Fowler MB, Bristow MR, et al: Safety and efficacy of carvedilol in severe heart failure. The U.S. Carvedilol Heart Failure Study Group. J Card Fail 3: 173-179, 1997.

27. Packer M, Fowler MB, Roecker EB, et al: Effect of carvedilol on the morbidity of patients with severe chronic heart failure: results of the carvedilol prospective randomized cumulative survival (COPERNICUS) study. Circulation 106: 2194-2199, 2002.

28. Yancy CW, Laskar S and Eichhorn E: The use of beta-adrenergic receptor antagonists in the treatment of African Americans with heart failure. Congest Heart Fail 10: 34-37, 2004.

29. López-Sendón J, Swedberg K, McMurray J, et al: Expert consensus document on beta-adrenergic receptor blockers. Eur Heart J 25: 1341-1362, 2004

30. Wood AJ: Racial differences in the response to drugs-pointers to genetic differences. N Engl J Med 344: 1394-1396, 2001. 